\title{
Desenvolvimento de Jogos Digitais como uma Estratégia para Despertar Novos Talentos: Um Relato de Experiência
}

\section{Cristina Paludo Santos, Denilson Rodrigues da Silva, Giana Ferreira, Maria Gisele Flores da Silveira}

\author{
Universidade Regional Integrada do Alto Uruguai e das Missões (URI) \\ 98.802-470 - Santo Ângelo - RS - Brasil \\ paludo@san.uri.br, deniro@san.uri.br, giana.ferreira.s@gmail.com, \\ guiga.flores.silveira@hotmail.com
}

\begin{abstract}
This article describes an experiment conducted with high school girls from public and private schools in a city of Rio Grande do Sul, in order to bring them to the computing area. The strategy used includes designing games for smartphones using the Construct 2 development environment. A description of the methodology applied and the results obtained is presented so that the experiment can be improved and replicated.
\end{abstract}

Resumo. Este artigo descreve uma experiência realizada com alunas do ensino médio de escolas públicas e privadas em um município do Rio Grande do Sul, com o intuito de aproximá-las da área de computação. A estratégia utilizada compreende a produção de jogos para smartphones utilizando o ambiente de desenvolvimento Construct 2. Uma descrição da metodologia aplicada e dos resultados alcançados é apresentada de modo que a experiência possa ser aprimorada e replicada.

\section{Introdução}

No decorrer da última década o ingresso de jovens e, em especial, de meninas em cursos de Ciência da Computação e Tecnologia da Informação tem diminuído de forma surpreendente. Ao mesmo tempo que crianças e adolescentes convivem cada vez mais com uma crescente gama de aparatos computacionais interativos, o contato frequente com esses dispositivos parece não implicar em um estímulo para que os alunos optem por carreiras relacionadas à tecnologia.

Dentre os motivos mencionados frequentemente destaca-se a falta de exploração de conceitos da computação aos estudantes na educação básica a fim de evidenciar a flexibilidade e potencialidades da área [França, 2015][Carter, 2016][Silveira, 2012]. Neste sentido, diversas estratégias têm sido propostas que extrapolam os aspectos funcionais das tecnologias, favorecendo uma compreensão mais ampla e profunda a fim de desenvolver no aluno a habilidade de "pensar computacionalmente" [Wing, 2008].

No conjunto das iniciativas existentes para o desenvolvimento dessa habilidade são recorrentes o uso de ambientes visuais de programação tais como Scratch [Oliveira, 2014] e App Inventor [Ramos, 2015][Santos, 2017a]; a promoção de atividades lúdicas por meio da computação desplugada [Ferreira et al, 2015; Santos, 2015]; robótica educacional [Almeida, 2015] e jogos digitais envolvendo lógica de programação [Falcão, 2015; Galdino, 2015; Pinho, 2016], sendo estes últimos o foco deste artigo. Jogos digitais são estratégias potenciais para o desenvolvimento do pensamento computacional, seja pela proposta interativa e desafiadora, seja pela possibilidade de trabalhar com o lúdico [Ferreira et. al, 2015]. Cardoso e Antonello (2015) destacam que a abordagem por meio de jogos no ensino/estruturação do pensamento 
VII Congresso Brasileiro de Informática na Educação (CBIE 2018)

Anais do XXIV Workshop de Informática na Escola (WIE 2018)

computacional demonstra ser motivadora e efetiva ao que se propõe, pois, os estudantes exercitam habilidades necessárias ao desenvolvimento integral, como a autodisciplina, a sociabilidade, a afetividade, valores morais, espírito de equipe e bom senso.

O presente trabalho insere-se neste elenco de iniciativas e apresenta a metodologia empregada na realização de uma oficina para produção de jogos. A iniciativa volta-se ao público feminino no espaço da educação básica, onde as primeiras expectativas de futuro e planejamento de carreiras são construídas. Cabe ressaltar que esta ação é uma das estratégias adotada no âmbito do Projeto Meninas Digitais Tchê Missões com vistas à mobilização do conhecimento e habilidades direcionadas ao objetivo de desenvolver o pensamento computacional e despertar novos talentos para a área, fomentando uma maior inclusão das mulheres no segmento de Tecnologia da Informação.

Uma visão geral das ações desenvolvidas é apresentada nas seções subsequentes. A seção 2 destaca algumas experiências realizadas por diferentes autores e que se alinham aos objetivos deste trabalho. As seções 3 e 4 apresentam, respectivamente, a metodologia aplicada e os resultados obtidos, a fim de compartilhar a experiência com a comunidade acadêmica de modo que possa ser aprimorada e replicada. Por fim, a seção 5 apresenta as considerações finais.

\section{Trabalhos Relacionados}

Introduzir tecnologia e o pensamento computacional na sala de aula está se tornando cada vez mais importante visto a forte influência da tecnologia no cotidiano de crianças e jovens. Segundo Wing (2006) a constituição do pensamento computacional apresenta-se como uma das mais importantes contribuições da ciência da computação para o mundo, pois forma cidadãos com competências e habilidades necessárias para conviver e prosperar em um mundo cada vez mais tecnológico e global.

Neste cenário, diferentes estratégias têm sido utilizadas. Vieira et al. (2013) propôs a produção de peças teatrais como estratégia para possibilitar aos participantes compreender os fundamentos da computação de forma clara e divertida. Já França (2015) propôs o uso do modelo penC em um curso de construção de jogos digitais como forma de introduzir conceitos de lógica de programação em iniciantes na área.

No que se refere aos aspectos motivacionais do uso de jogos digitais na educação, os mesmos são discutidos na literatura praticamente desde o início da popularização desse tipo de jogo. Prensky (2004) já argumentava que os jogos digitais fazem parte do contexto cultural das gerações nascidas após a década de 1980, e que isso justificaria o seu uso com finalidade educacional de forma mais efetiva.

Mais recentemente, Denner et.al. (2012) argumentam que, a partir do desenvolvimento de jogos digitais, os jovens constroem competências relacionadas ao desenvolvimento de mídias interativas e aos fundamentos da programação. Além disso, os autores apontam que os aspectos relacionados à qualidade da interação humano-computador em jogos desenvolvidos por alunos servem também como um relevante aspecto motivacional. Neste contexto, uma atividade sem o uso de computadores é apresentada por Maciel et al. (2012). Marinho et al. (2011) apresentam e discutem vários episódios didáticos em que aspectos relacionados à interação humanocomputador em jogos digitais construídos por alunos apresentam um potencial para a mobilização de conhecimentos interdisciplinares. 
Tais iniciativas, apesar de utilizarem diferentes estratégias, convergem em sua finalidade disseminando o pensamento computacional como forma de atrair os jovens para a área de computação e, a partir disso, inspirar novos talentos. Estas iniciativas demonstraram resultados positivos e negativos em seus desenvolvimentos. Tais resultados foram importantes para que as ações pudessem ser otimizadas e replicadas no presente trabalho.

\section{Metodologia}

A oficina de produção de jogos inclui atividades que visam evidenciar o potencial criativo, a competência, a inteligência e as habilidades que as meninas possuem para produzir tecnologias e não apenas para utiliza-las. A programação incluiu a realização de ateliers de programação que consistiram em 6 encontros onde foram explorados conceitos relacionados ao desenvolvimento de jogos tais como, a animação de sprites, colisão, controles de teclado e mouse; fundamentos de programação como, variáveis, estruturas condicionais, laços e mensagens; e a interação humanocomputador, com destaque para as heurísticas de jogabilidade [Barcelos, 2011].

Nestes encontros utilizou-se uma abordagem teórico-prática. Inicialmente houve a familiarização com o ambiente do Construct 2. Foi escolhido o Construct 2 como ferramenta de desenvolvimento visto que permite que usuários com pouca ou nenhuma experiência prévia com fundamentos de programação produzam programas com funcionalidades razoavelmente sofisticadas. A cada conceito teórico abordado uma atividade prática foi desenvolvida na ferramenta a fim de demonstrar como o conceito é aplicado na prática de implementação de jogos. A Figura 1 apresenta registros das atividades realizadas nos 5 primeiros encontros.

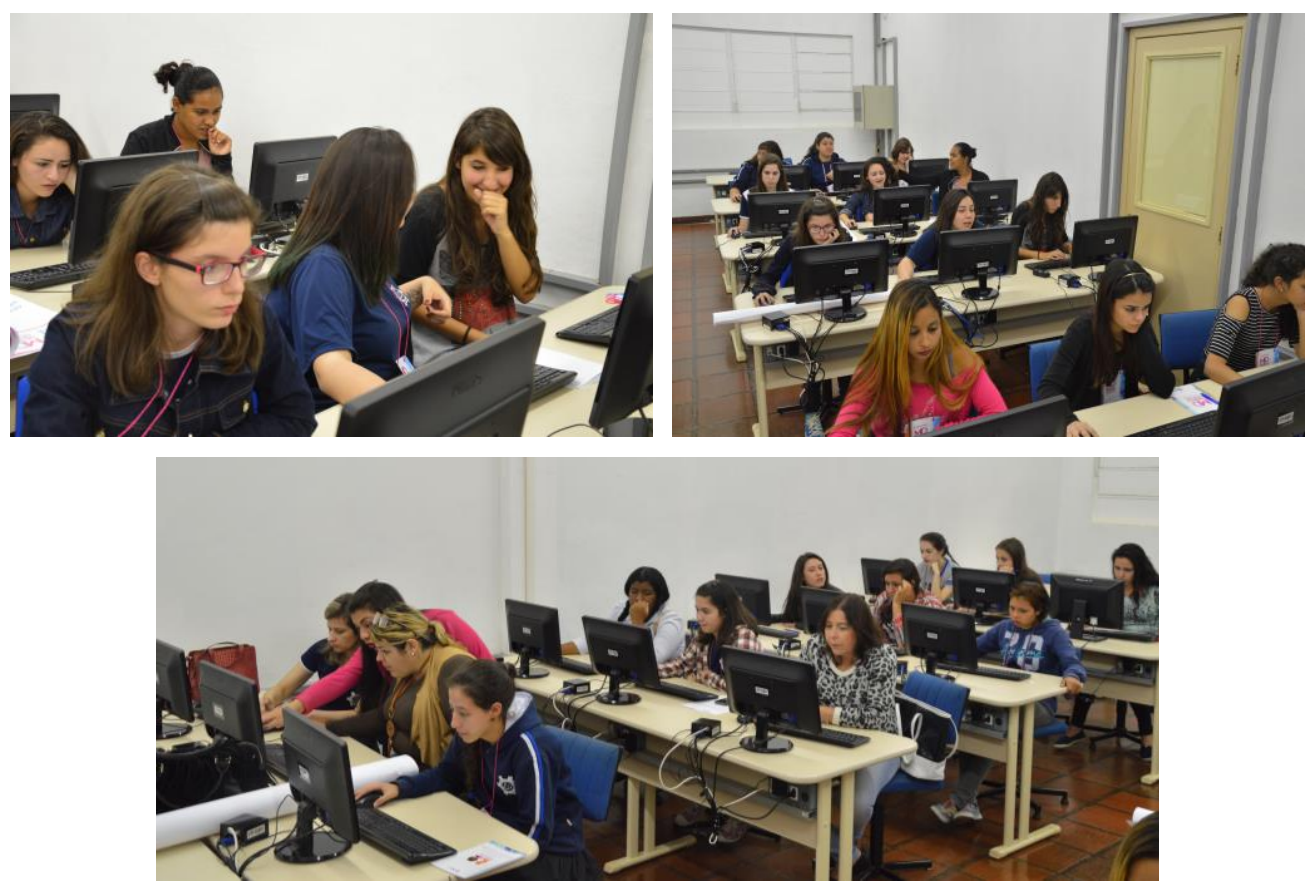

Figura 1. Meninas do ensino médio participando da oficina de produção de jogos digitais

Uma vez assimilados os conceitos, a partir da sexta semana, as equipes foram instigadas a participar de um desafio de programação onde deveriam criar um jogo digital voltado para o contexto educacional. Assim, como parte das atividades também foram promovidas oficinas de brainstorming e pitch (sexto e sétimo encontro). O brainstorming é uma técnica de inovação e geração de ideias em conjunto. A Figura 2 apresenta alguns registros do processo de ideação 
onde as participantes levantaram problemas e propuseram soluções.
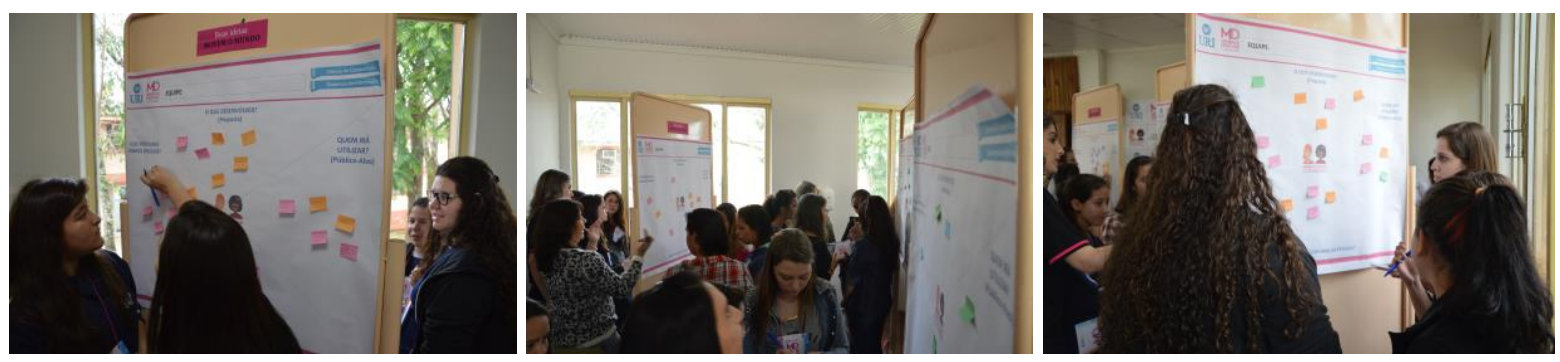

Figura 2. Atividade de ideação de jogos voltados à Educação

Já, o pitch é uma apresentação rápida de uma ideia/projeto, utilizado para gerar interesse das pessoas e atrair os recursos necessários para concretiza-la. Através desta prática, as participantes exercem a arte de vender suas ideias, aprimoram a capacidade de comunicação em público, desenvolvem habilidades de improvisação, essencial para o momento de perguntas e respostas, dentre outros. Assim, uma vez definidas as ideias a serem implementadas no desenvolvimento dos jogos, cada equipe apresentou-as por meio de um pitch. Por meio destas atividades buscou-se prover um espaço para que meninas com interesse em tecnologia pudessem conversar, trocar experiências e pensarem projetos.

Os últimos 4 encontros foram destinados à produção do jogo proposto por cada equipe. Nesses encontros as equipes tiveram a oportunidade de discutir e refletir sobre a mecânica de cada jogo, desenvolvendo aspectos do pensamento computacional relacionados à automação e, consequentemente, a conceitos de programação de computadores. Ao analisar as funcionalidades adicionais incluídas com mais frequência pelos alunos, foi observada a recorrente necessidade dos alunos explorarem espontaneamente conceitos de programação que ainda não haviam sido usados por eles em nenhum momento. Em outros episódios, a orientação do professor faz com que o aluno passe a contextualizar a necessidade de usar um conceito já explorado em atividades anteriores.

Os jogos desenvolvidos contemplaram domínios de aplicação como: ensino de matemática; orientações sobre a prática de exercícios físicos em academias ao ar livre; doação de sangue e doação de órgãos; coleta seletiva de lixo; incentivo ao uso de transporte coletivo; dentre outros. Todas as equipes participaram de uma competição onde a seleção dos 3 melhores jogos foi realizada por uma comissão de avaliação. Os critérios considerados no processo avaliativo incluíram questões de usabilidade, jogabilidade, originalidade, design gráfico, funcionalidade e qualidade do pitch. A competição culminou em uma cerimônia de premiação e encerramento, onde os 3 melhores jogos foram premiados com troféus e medalhas. Todas as participantes receberam certificado de participação.

No total foram realizados 12 encontros, que ocorreram semanalmente com duração aproximada de três horas e meia, em turno inverso às atividades escolares. Todos os encontros foram realizados na instituição proponente.

A oficina de produção de jogos contou com a participação de 54 meninas, do ensino médio, provenientes de escolas públicas e privadas do município. As meninas compunham 13 equipes, sendo que cada equipe contava com um professor da escola como responsável. Adicionalmente, atuaram no projeto 2 docentes da computação e 2 alunas do ensino superior. 
VII Congresso Brasileiro de Informática na Educação (CBIE 2018)

Anais do XXIV Workshop de Informática na Escola (WIE 2018)

\section{Resultados Obtidos}

Os resultados desta experiência permitiram uma aproximação maior com a realidade das meninas no que se refere ao contato com a tecnologia. Além dos jogos desenvolvidos, outros resultados foram obtidos a partir de uma análise qualitativa realizada à luz da interpretação de especialistas em tecnologia educacional a partir das respostas de questionários aplicados no início e no término das atividades. As análises geradas abarcam aspectos de comportamento em relação ao uso de tecnologias, interesse pela área de computação e, experiência do usuário em relação as atividades propostas.

No levantamento inicial realizado, as meninas foram arguidas sobre sua área favorita sendo que $28 \%$ das meninas apontaram exatas, $32 \%$ biológicas e $40 \%$ humanas. Das meninas que preferem a área de exatas 5 delas afirmaram ter interesse em realizar um curso superior na área de tecnologia. Para as demais, ciência de computação ou quaisquer outros cursos ligados à área não era uma opção de curso. Arguidas sobre os motivos que as levam a não pensar na computação como uma possibilidade de profissão futura obteve-se os seguintes resultados: $32 \%$ relacionam a área com o público masculino, $25 \%$ não sabem exatamente o que é ensinado nos cursos da área, $45 \%$ veem a computação como uma área difícil que envolve muita matemática.

Grande parte das meninas $(75 \%)$ indicaram ter apenas uma noção sobre as competências e habilidades de um profissional de computação. Além disso, $96 \%$ não sabiam como funcionava um programa de computador, mas se mostraram motivadas para aprender a programar um.

Após a realização da oficina de produção de jogos $43 \%$ das estudantes declararam um acréscimo de interesse pela área de Computação passando a cogitar a possibilidade de cursar computação, mas como segunda opção. Além disso, 96\% afirmaram que utilizarão os conhecimentos obtidos e relacionados à programação para desenvolvimento de trabalhos em várias disciplinas, alegando que o uso "vai ser um diferencial dos meus trabalhos em relação a outros". Isto demonstra que os conteúdos abordados foram assimilados de forma satisfatória e que os conhecimentos construídos em Computação, junto com suas tecnologias, implicarão em um melhor desenvolvimento do seu trabalho, na busca e construção de soluções em outros contextos. Apenas $4 \%$ das meninas alegaram ter apresentado dificuldades na resolução dos desafios propostos, mas destacam que a utilização do ambiente foi um instrumento interessante e favorecedor da aprendizagem.

Das meninas participantes $85 \%$ afirmaram que gostariam de participar de outras edições ou cursos para aprender mais sobre computação. Estes dados demonstram uma discrepância em relação ao interesse das meninas em aprender mais sobre computação e o interesse em realizar um curso superior na área. Tais resultados comprovam a necessidade de novas pesquisas e estudos que possam prover dados mais significativos em relação aos motivos dessa discrepância.

Todas as meninas participantes do projeto foram indagadas sobre sua percepção das iniciativas promovidas no âmbito do projeto X. Dentre as declarações destacam-se: "Estou adorando tudo que estou aprendendo." (J.D, 17 anos); "Não imaginava que pudesse desenvolver um jogo. Adorei. Quero desenvolver outros e aprender mais coisas" (B.S, 16 anos); "Está sendo uma experiência incrível." (I.F, 15 anos); "Quero participar das outras atividades do projeto. Gostei muito." (M. A, 17 anos). A partir destas declarações percebe-se que há interesse das meninas pela área tecnológica, o que falta são iniciativas que oportunizem o contato das mesmas com este universo. 
VII Congresso Brasileiro de Informática na Educação (CBIE 2018)

Anais do XXIV Workshop de Informática na Escola (WIE 2018)

Os resultados acima demonstram que ações como esta que foram propostas são valiosas para esclarecer muitas dúvidas que ainda pairam sobre a área de computação. Além disso, acredita-se que os resultados deste tipo de iniciativa possam surtir efeitos favoráveis no que se refere ao aumento do número de meninas na área a médio e longo prazo. Evidencia-se ainda como resultado positivo desta experiência o interesse das escolas e alunas em participar de novas edições do projeto, o que demonstra a boa repercussão da experiência nos espaços escolares.

\section{Considerações Finais e Trabalhos Futuros}

Atualmente, percebe-se uma crescente oferta de atividades didáticas desenvolvidas com o objetivo de fomentar aspectos do pensamento computacional junto a estudantes do ensino básico a fim de desenvolver novas competências e habilidades do "fazer" Computação e não apenas utiliza-la. Dentre as diferentes estratégias adotadas para este fim destaca-se, neste trabalho, a produção de jogos digitais.

O notável interesse dos jovens por jogos digitais, atrelado às várias contribuições já destacadas por diversos autores no que se refere ao uso/produção de jogos para fins educacionais, foram fatores predominantes na escolha do escopo a ser abordado na oficina. A produção de jogos digitais tem um apelo especial, pois agregam ludicidade, motivação e desafio aos processos de aprendizagem (remetendo à "aprendizagem baseada em jogos digitais" [Prensky, 2004]). Além disso, envolvem pensamento computacional, estimulam o raciocínio lógico através de definição de estratégias, tomadas de decisão e resolução de problemas, em contextos interativos e de rápido feedback.

Os resultados revelaram que a produção de jogos digitais em experiências de aprendizagem é substancialmente benéfica, visto que provoca grande motivação dos alunos e apresenta-se como uma estratégia potencializadora da ampliação de espaços de aprendizagem, exploração do pensamento computacional e aproximação dos jovens para a área da Computação. Neste cenário, acredita-se que as ações propostas contribuem para estimular um maior interesse dos estudantes em carreiras relacionadas à Computação; complementar a formação de jovens imersos em uma cultura digital, independentemente das carreiras que venham a seguir e, sobretudo, quebrar estigmas e contribuir para dirimir a reverberação do estereótipo de que Computação é "coisa de menino", servindo como ponto de apoio à consolidação da imagem de que os espaços de Ciência e Tecnologia são também lugares onde as mulheres podem e devem ocupar.

\section{Referências Bibliográficas}

Almeida, Carlos Manuel dos Santos. A importância da aprendizagem da robótica no desenvolvimento do pensamento computacional: um estudo com alunos do $4^{\circ}$ ano. Tese de Doutorado. Universidade de Lisboa, 2015.

Barcelos, Thiago Schumacher et al. Análise comparativa de heurísticas para avaliação de jogos digitais. In: Proceedings of the 10th Brazilian Symposium on Human Factors in Computing Systems and the 5th Latin American Conference on Human-Computer Interaction. Brazilian Computer Society, 2011. p. 187-196.

Cardoso, Rogério; Antonello, Sérgio. Interdisciplinaridade, programação visual e robótica educacional: relato de experiência sobre o ensino inicial de programação. In: Anais dos Workshops do Congresso Brasileiro de Informática na Educação. 2015. p. 1255. 
VII Congresso Brasileiro de Informática na Educação (CBIE 2018)

Anais do XXIV Workshop de Informática na Escola (WIE 2018)

Carter, L. "Why students with an apparent aptitude for computer science don't choose to major in computer science," Sigcse Bull, vol. 38, no. 1, pp. 27-31, Mar. 2016.

Denner, J.; Werner, L.; Ortiz, E. "Computer games created by middle school girls: Can they be used to measure understanding of computer science concepts?”. Comput. Educ., vol. 58, no. 1, pp. 240-249, Jan. 2012.

Falcão, Taciana Pontual; BARBOSA, Rafael. (2015) " Aperta o Play!" Análise da interação exploratória em um jogo baseado em pensamento computacional. In: Simpósio Brasileiro de Informática na Educação-SBIE. 2015. p. 419.

Ferreira, Ana Carolina, et al. "Experiência prática interdisciplinar do raciocínio computacional em atividades de computação desplugada na educação básica." In: Anais do Workshop de Informática na Escola. Vol. 21. No. 1. 2015.

França, Rozelma; Tedesco, Patrícia. Desafios e oportunidades ao ensino do pensamento computacional na educação básica no Brasil. In: Anais dos Workshops do Congresso Brasileiro de Informática na Educação. 2015. p. 1464.

Galdino, C.; Silva, S. R. N; Costa, E. B. Planejando um serious game para a prática de Programação. In: IV Congresso Brasileiro de Informática na Educação - CBIE 2015 / X Conferência Latino-Americana de Objetos e Tecnologias de Aprendizagem. Maceió, Sociedade Brasileira de Computação: 2015.

Maciel, C., Bim, S. A.; Boscarioli, C. "A fantástica fábrica de chocolate: levando o sabor de IHC para meninas do ensino fundamental," in Companion Proceedings of the 11th Brazilian Symposium on Human Factors in Computing Systems, Porto Alegre, Brazil, Brazil, 2012, pp. 27-28.

Marinho, F. C. V.; Giannella, T. R.; Struchiner, M. "Estudantes do Ensino Básico Como Desenvolvedores de Jogos Digitais: Contextos Autênticos de Aprendizagem para Educação em Ciências e Matemática," in Atas do VIII Encontro Nacional de Pesquisa em Educação em Ciências, Campinas, 2011.

Oliveira, Millena Lauyse Silva, et al. "Ensino de lógica de programação no ensino fundamental utilizando o Scratch: um relato de experiência." In: Anais do XXXIV Congresso da SBCXXII Workshop de Ensino de Computação, Brasília. 2014.

Pinho, Gustavo et al. Proposta de Jogo Digital para Dispositivos Móveis: Desenvolvendo Habilidades do Pensamento Computacional. In: Anais do Simpósio Brasileiro de Informática na Educação-SBIE. 2016. p. 100.

Prensky, M, Digital Game-Based Learning. Washington: McGraw-Hill Pub. Co., 2004.

Ramos, Nadja et al. Ensino de programação para alunas de ensino médio: Relato de uma experiência. In: XXIII Anais do Workshop sobre Educação em Computação. 2015.

Santos, Elisângela Ribas et al. Estímulo ao Pensamento Computacional a partir da Computação Desplugada: uma proposta para Educação Infantil/Stimulus to computational thinking: a proposal for elementary school. Revista Latino-americana de Tecnología EducativaRELATEC, v. 15, n. 3, p. 99-112, 2016. 
Santos, Mateus Paludo; Santos, Cristina Paludo; Ellwanger, Cristiane. A Computação sob a Ótica de Meninas do Ensino Médio. In: Anais do XI Woman Information Technology Congresso da Sociedade Brasileira de Computação: WIT. São Paulo: SBC, 2017.

Santos, Cristina Paludo; Silva, Denilson Rodrigues da; Silveira, Maria Gisele; Ferreira, Giana. Desafio de Programação para Meninas do Ensino Médio: Um Relato de Experiência. In: Anais do XXIII Workshop de Informática na Escola (WIE 2017) VI Congresso Brasileiro de Informática na Educação (CBIE 2017). Recife: SBC, 2017.

Silveira, I. F; Barcelos, T. S.; "Teaching computational thinking in initial series," in Proceedings of CLEI 2012, Medellín, 2012.

Vieira, A., Passos, O. and Barreto, R. Um Relato de Experiência do Uso da Técnica Computação Desplugada. In: Anais do XXI Workshop sobre Educação em Computação. SBC, 2013. p. 670-679.

Wing, J. M. Computational thinking and thinking about computing. Philosophical Transactions of the Royal Society A: Mathematical, Physical and Engineering Sciences, v. 366, n.1881, p. 3717-3725, 2008. 